\title{
Editorials
}

\section{Childhood sexual abuse and psychosis: aetiology and mechanism}

\author{
PAUL BEBBINGTON
}

\begin{abstract}
The aim of this Editorial is to describe the association between child sexual abuse and psychosis, and to consider potential mechanisms for the association. The association is strongly supported by the literature. Evidence from a variety of sources is triangulated in order to create a plausible model of the link, which can then be used to direct future research. The mechanisms are certainly complex, and there is evidence of interacting contributions at genetic, neurophysiological, behavioural, cognitive and emotional levels. Child sexual abuse is an important antecedent in psychosis, both theoretically and clinically. At the theoretical level, it potentially illuminates mechanisms by which psychotic symptoms are generated, at the clinical level it opens possibilities for improving cognitive-behavioural approaches to treatment.
\end{abstract}

Declaration of Interest: None.

KEY WORDS: sexual abuse in childhood, psychosis, mechanism of psychiatric symptoms.

\section{INTRODUCTION}

The place of stress in the emergence of psychotic symptoms has been the subject of clinical contention in psychiatry for over a century (Bebbington et al., 1993). Empirical studies of recent stressful events date back to the 1960 s, the events being seen as triggers, the last element in the aetiological chain (Brown \& Birley, 1968). It has never been clear over what period events exert their effects, whether the few weeks before onset or a more prolonged period of months (Day et al., 1987; Ventura et al., 1989; Hultman et al., 1997; Dohrenwend et al., 1987; Bebbington et al., 1993; Hirsch et al., 1996). Indeed some studies found no association between life events and onset (Jacobs \& Myers, 1976; Malzacher et al., 1981; Al Khani et al., 1986; Chung et al., 1986; Gureje \& Adewumni, 1988; Malla et al., 1990; Hirsch et al.,1996). Nevertheless the research does suggest overall that in some cases stressful social circumstances are closely associated with the emergence of schizophrenia.

Address for correspondence: Professor P. Bebbington, UCL Department of Mental Health Sciences, 2nd Floor, Charles Bell House, 67-73 Riding House Street, London W1W 7EJ (United Kingdom). Fax: 020-7679.9426

E-mail: P.Bebbington@ucl.ac.uk
Over the last decade or so, the focus has moved away from the effect of recent stress to the study of much earlier social adversity in people who develop schizophrenia. This has been tied conceptually to the stress-vulnerability paradigm. As originally framed, this carried the implicit view that vulnerability in schizophrenia is genetic, or perhaps related to the early physical environment. There was considerable reluctance to attribute to social factors effects of a greater persistence than those implied by mere triggering. However, genetic and biological indicators of vulnerability are far from universal in individuals with schizophrenia (Tosato \& Lasalvia, 2009), and there is certainly no logical reason why vulnerability should not in some cases be psychosocial, arising from adverse experiences early in life (Read et al., 2001).

Childhood adversity takes many forms (Morgan \& Fearon, 2007). It may include actual abuse, whether physical, sexual or emotional. Such abuse seems to be common. Thus, a recent UK survey found a prevalence of $24 \%$ for childhood physical abuse and of $11 \%$ for sexual abuse (May-Chahal \& Cawson, 2005); even higher estimates have been reported from the USA (Friedman et al., 2002). The estimates depend on the definition, and on how many types of events are used as prompts. Increasing attention is also being paid to the serious effects of bullying, whether inside or outside school. Approximately $17 \%$ of children from a nationally repre-

Epidemiologia e Psichiatria Sociale, 18, 4, 2009 
sentative birth cohort in the UK reported being bullied by the age of seven years (Arseneault et al., 2006).

While the deleterious effects of childhood trauma are now well established, they seem relatively non-specific. Thus there is an enhanced risk of adult depression, personality disorder, PTSD, drug and alcohol abuse, and suicidality (Bebbington et al., 2004; 2009). Nevertheless, there is now increasing evidence of strong, perhaps particularly strong, links with psychosis. Set against this there have been concerns about the reliability of reports of abuse in people whose mental state is affected by schizophrenia. However, Goodman et al. (1999) showed that their accounts are consistent over time, and concluded that the information obtained is sufficiently reliable to allow research in this area.

\section{Childhood abuse in people with psychosis}

Ellason \& Ross (1997) found a significant association of child physical and sexual abuse with psychotic symptoms, confirmed by Mueser et al. (1998). Lysaker et al. (2001) found $40 \%$ of a sample of people with schizophrenia acknowledged child sexual abuse. In the British National Psychiatric Morbidity Survey, the relative odds of psychosis were around 12 in people who had experienced sexual abuse (Bebbington et al., 2004).

Janssen et al. (2004) showed that childhood abuse predicted the development de novo of positive psychotic symptoms in members of the general population over a two-year period. Ukok \& Bikmaz (2007) found child sexual abuse is especially associated with the positive symptoms of psychosis in patients with first episodes of schizophrenia. If true, this might indicate some specifity of mechanism for positive symptoms.

Reviewing the literature linking childhood trauma to psychosis, Read et al. (2005) felt able to conclude that the link was now well established. Morgan \& Fisher (2007) have been more cautious, acknowledging that recent population-based studies provide robust evidence of an association, but pointing out several conceptual and methodological issues.

In addition to its effect on the emergence of psychotic symptoms, an adverse early environment may contribute to their maintenance. Thus it may lead to chronicity and poor outcome in people who do develop psychosis. Fowler (1999) found that histories of severe early trauma were more common in people with chronic psychosis than in those in their first episode (who include a proportion heading for a good outcome). In a German study, traumatic experiences and adverse circumstances in childhood were related to outcome in the form of relapse and rehospitalization (Doering et al., 1998). Sub-clinical symptoms of psychosis may also be abnormally persistent in people with early trauma (Cougnard et al., 2007).

\section{PTSD and psychotic symptoms}

Evidence is also accumulating of a close relationship between post-traumatic stress disorder (PTSD) and psychotic symptoms. This is worth examining in some detail, as it has obvious implications for persistent effects of stress in the aetiology of schizophrenia.

One place to search for such links is in military personnel. Psychotic symptoms in response to combat trauma were reported by Paster as long ago as 1948, and are not uncommon. Forty per cent of one sample of Vietnam veterans had experienced psychotic symptoms in the 6 months before assessment (David et al., 1999). Calhoun et al. (2007) provide evidence that, although commonly under-diagnosed, PTSD is highly prevalent in war veterans with schizophrenia. Hamner et al. (2000) compared veterans displaying long-standing PTSD and psychotic features with a sample of patients with schizophrenia without PTSD. They found very few differences in the form and intensity of the psychotic features, either positive or negative, suggesting that schizophrenia associated with PTSD is indistinguishable clinically from the condition in general.

Rates of PTSD in people with psychosis are also relevant here. Mueser et al. (1998) studied 275 patients with a range of severe mental disorders, largely psychosis. Forty-three per cent had PTSD as a result of a severe trauma at some stage of their lives, often in childhood. However, only in $2 \%$ was the diagnosis recorded in their notes. Ninety-eight per cent of the sample had been exposed to at least one severe trauma. Seedat et al. (2003) systematically reviewed the association between PTSD and psychosis. Rates of serious trauma were generally very high in people with psychosis, while rates of actual PTSD were lower, although substantial, ranging from $13 \%$ to over $50 \%$. The figures vary with the method of assessment (Priebe et al., 1998; Neria et al., 2002; Resnick et al., 2003; Kilcommons \& Morrison; 2005; Shevlin et al., 2007).

The severity of trauma is associated with the severity both of PTSD and of psychotic symptoms, and also with current levels of distress and poor psychosocial functioning (Resnick et al., 2003; Lysaker et al., 2001; Kilcommons \& Morrison, 2005). Thus early trauma appears to create a plethora of interacting adverse conse-

Epidemiologia e Psichiatria Sociale, 18, 4, 2009 
quences, leaving the mechanism linking traumatic and psychotic symptoms open to interpretation.

Mueser et al. (2002) argue that PTSD may mediate the negative effects of trauma on the course of severe mental illness. This may operate both directly, through the capacity of PTSD to affect symptom generation in psychosis, and indirectly, through retraumatization, substance abuse and social difficulties. Both channels are probably important. Traumatic early life experiences predispose individuals both to psychosis and to substance abuse. The substance abuse often makes outcome worse: childhood trauma and PTSD both seem especially frequent in dual diagnosis patients (Scheller-Gilkey et al., 2004). Gearon et al. (2003) found particularly high rates of traumatic life events in women with psychosis and comorbid substance abuse: revictimization was common, and rates of concurrent PTSD were especially high.

PTSD is a condition defined essentially by an intimate relationship between the experience of strongly traumatic events and the content of symptoms, in particular the phenomenon of re-experiencing. One possibility is that some people exposed to extreme trauma develop psychotic symptoms (delusions, hallucinations) whose content is also closely related to the details of the traumatic experience. If this happens, it may represent a totally different process from that responsible for symptoms in the majority of cases of schizophrenia, or it may not.

Some might argue that florid symptoms in PTSD merely mimic psychotic symptoms. Thus, re-experiencing may have a compelling visual or auditory quality capable of being mistaken for hallucinations. However, even in veterans exposed to extreme combat stress, the distinction between flashbacks and psychotic symptoms can be clearly made (Ivezic et al., 1999).

\section{Trauma and hallucinations}

Hallucinations seem to be particularly frequent in psychoses associated with trauma, thus, in all but one case of Vietnam veterans with psychosis studied by David et al. (1999), their symptoms included auditory hallucinations. Kilcommons \& Morrison (2005) found that sexual abuse was related specifically to hallucinations. This may be particularly true of child sexual abuse, while adult sexual assault may be related more generally to the full range of schizophrenic psychopathology (Read et al., 2003). This trauma/hallucination link is not restricted to schizophrenia: trauma appears just as strongly associated with auditory hallucinations in bipolar disorder (Hammersley et al., 2003). Again the link seems particularly strong for child sexual abuse.
However, Hardy et al. (2005) found that, in many cases where trauma preceded hallucinations, the hallucinations were only thematically related to the trauma, and did not often involve actual recapitulation of the traumatic event. Thus women with a history of rape often hear voices calling them obscene and denigrating names. In other studies as well, meaningful connections between the characteristics of trauma and the content of symptoms are not always apparent. Butler et al. (1996) felt that, in their series, the psychotic symptoms associated with PTSD were not themselves linked to re-experiencing the trauma. Likewise, in a military study, the severity of psychotic symptoms associated with combat-related PTSD was correlated with the severity of PTSD symptoms, but there was no apparent link between psychotic symptoms and re-experiencing the traumatic event per se (Hamner et al., 1999). From this, it appears almost as though psychotic symptoms are an alternative way of re-experiencing.

\section{Trauma, dissociation and psychosis}

Another aspect of the trauma/PTSD/psychosis triad concerns the salience of dissociative processes. Glaslova et al. (2004) have suggested that traumatic stress exerts its influence on schizophrenia precisely by increasing the tendency to dissociation. Holowka et al. (2003) certainly found that childhood trauma was associated with significant dissociative symptoms in people with schizophrenia. Kilcommons \& Morrison (2005) likewise found that dissociative processes consequent upon trauma were linked to psychotic experiences, and with hallucinations in particular. Irwin (2001) suggested that dissociative experiences and PTSD were connected because both were associated with childhood trauma, although controlling for childhood trauma did not remove the association. However, there are difficulties in defining and identifying dissociative processes, and the association with schizophrenia is not universally accepted (Brunner et al., 2004).

\section{Mechanisms of the stress-psychosis link}

In the origination of psychosis, stress almost certainly operates at more than one level. It appears to trigger the emergence of psychotic symptoms, and people with psychosis may in any case have a particular vulnerability to stress. However, this vulnerability in turn may be the consequence of earlier stresses. There has been considerable speculation (and some research) about the mechanisms by which triggering, vulnerability and early adver- 
sity exert their effects. This triangulates the stress/psychosis relationship in a way that increases its plausibility.

There are several levels at which vulnerability to stress can be characterized in psychosis. Genetic, neurophysiological, affective, cognitive and behavioral abnormalities may be demonstrable, and may interact. Current models of vulnerability are speculative but nonetheless valuable if they direct and drive future research.

The emergence of psychotic symptoms is a relatively uncommon response to stress: the more usual response involves affective symptoms. Thus, explaining the triggering of psychosis without adducing a pre-existing personal vulnerability would rely on the postulation of normal individuals facing an abnormal concatenation of circumstances, perhaps invoking affective changes and specific appraisals. The current cognitive models of psychosis emphasize both the person's appraisal of the impact of stress and the ensuing cognitions and emotions, and how they might interact with perceptual abnormalities (Fowler, 2000; Garety et al., 2001; 2007; Bentall et al., 2001; Morrison, 2001; Birchwood, 2003; Broome et al., 2005).

There is appreciable evidence that individuals with a prior history of psychotic symptoms do respond to stressful circumstances with normal anxiety and depression. Such affective changes are also seen in the prodromal period before the emergence or re-emergence of psychotic symptoms. Ventura et al. (2000) showed that the recurrence of psychotic symptoms is not the only response to stressful life events in people who have experienced prior episodes of schizophrenia. In many instances, the exacerbation does not proceed beyond non-psychotic depressive symptoms. This links into the literature on affective prodromes of relapse (Birchwood et al., 1992), not all of which lead to the re-emergence of psychotic symptoms (Yung \& McGorry, 1996). Myin-Germeys et al. (2005) were able to show that the clear affective response to small stressors was paralleled by moment-to-moment variation in subtle positive psychotic experiences.

Mood and cognitive attributes seem to have independent associations with psychotic and quasi-psychotic symptoms in clinical and non-clinical populations (Garety et al., 2005; Fowler et al., 2006; Smith et al., 2006; Bentall et al., 2009). In these studies, a combination of anxiety and schematic views of the self as weak, vulnerable, and inadequate, and of other people as devious, threatening, and bad, was found to be specifically associated with paranoia. Such cognitions have been adduced to explain the excess of psychosis in some immigrant groups (Cooper et al., 2008).

What of the biological correlates of stress in schizophrenia? At one level these correspond to the stress responses of normal people, although, as we shall see, there is always a tendency to invoke a modifying vulnerability in people with schizophrenia. In patients newly admitted with an acute episode of psychosis, the severity of recent life stressors was proportionate to the increase in serum cortisol (Mazure et al., 1997). People with first episode psychosis may display increased HPA axis activation (Ryan et $a l .$, 2004). There is even evidence that the onset of psychosis may be associated with actual pituitary enlargement (Pariante et al., 2005). Jones \& Fernyhough (2007) incorporated the modulation of cortisol production by stress into their neural diathesis-stress model of schizophrenia. They suggested, further, that cortisol is most strongly produced in response to situations that imply uncontrollable threats to social standing or to important goals.

While cortisol metabolism is central to the normal stress response, the predominant explanation of anomalous experiences in schizophrenia has been couched in terms of the dopamine theory. There is converging evidence from animal research and clinical studies supporting a role for dopamine dysregulation in the prefrontal cortex in schizophrenia (e.g. Goldman-Rakic et al., 2004; Kapur et al., 2005). However, dopamine release is also a recognized response to stress in non-psychotic individuals (Adler et al., 2000; Pruessner et al., 2004). For this reason it remains possible that schizophrenic symptoms might arise in the absence of vulnerability, for instance if the degree of stress were overwhelming, as in psychoses following war trauma.

Vulnerability may operate at the behavioural level, involving, for instance, impaired coping mechanisms and ineffective ways of accessing support (Hultman et al., 1997; MacDonald et al., 1998). Pallanti et al. (1997) provide evidence of sensitivity to events in terms of coping deficits. Patients whose relapse did not follow a life event in the month before relapse showed less effective coping and poorer information processing capacity. The implication is that patients who have good coping resources (including cognitive capacity) will only be unsettled by events of considerable threat, in contrast to those without.

Horan et al. (2007) compared responses to the 1994 Californian earthquake in people with schizophrenia, those with bipolar disorder and healthy controls (Horan et al., 2007). Both patient groups reported a high level of avoidant symptoms on the Impact of Events Scale. Moreover, avoidant coping was associated with higher residual stress symptoms in the schizophrenia group at follow-up. Horan \& Blanchard (2003) showed that patients with schizophrenia responded with more negative mood if they had maladaptive coping styles and trait negative affectivity. 
Horan et al. (2005) reported that, compared with controls, patients with schizophrenia appraised events as less controllable, and thought they had handled them less well. They also down-rated positive events. The psychological mediation of vulnerability to stress may also involve hopelessness. This is very common in people who have newly developed schizophrenia, and appears to be linked to poor outcome (Aguilar et al., 1997).

The ability to access social support may represent a behavioral component of vulnerability. There is an extensive literature in the study of depression directed at the stress-buffering function of social support (Alloway \& Bebbington, 1987). Hultman et al. (1997) have investigated schizophrenia in similar terms: they found that the time between events and relapse was increased in people with better social support and a coping strategy characterized by active support seeking. Penn and his colleagues (2004) have also suggested a role for social support in maintaining recovery.

Vulnerability to stress may vary over time, and there have been suggestions that the experience of an episode of psychosis may itself alter sensitivity, a sort of scarring process. In bipolar disorder, it has been suggested that life events may only be in excess in early episodes, and that later episodes appear less associated with events because of the process of kindling (Ramana \& Bebbington, 1995). There has been little examination of this possibility in schizophrenia: in a small study $(n=32)$ of American veterans, life events were more likely to be associated with earlier episodes of schizophrenia (Castine et al., 1998), although others have not found this (Bebbington et al.,1996).

Life events themselves may modulate the increased sensitivity of patients with psychosis to day-to-day stress (Read et al., 2001; Myin-Germeys et al., 2003). Moreover, the risk may accumulate over time, as more adverse experiences occur (Myin-Germeys \& van Os, 2007). Myin-Germeys et al. (2003) found that the increased sensitivity of patients with psychosis to day-today stress assessed using the Experience Sampling Method (ESM) was markedly modulated by the background life event rate. They took this as evidence for a separate, affective, route to symptom formation in psychosis, characterized by a more episodic reactive type of psychosis with a relatively good outcome.

The mechanisms of vulnerability could in part be gene-environmental. Thus Kinderman \& Cooke (2000) interpreted the Finnish study of Tienari et al. (1994) as indicating that the family environment was playing a crucial part in moderating genetic risk. Read et al. (2001), however, argued for a direct biological effect of adverse life events in early life on the diathesis underlying psychosis, thus positing a traumagenic neurodevelopmental model of schizophrenia. There is some suggestion that patients with a history of childhood trauma have reduced hippocampal volume (Driessen et al., 2000); this is also seen in people experiencing a first episode of psychosis (Shenton et al., 2001; Lappin et al., 2006). Childhood adversity may also induce lasting effects on the main hormonal stress response system, the hypothalamico-pituitary-adrenal (HPA) axis (Read et al., 2005: Spauwen et al., 2006). Women physically or sexually abused in childhood show HPA disregulation (Heim et al., 2000).

Trauma may exert its effect on vulnerability through the induction of persistent affective changes. Mood may have persistent as well as temporary effects on the propensity to develop schizophrenic symptoms. Dinzeo et al. (2004) suggest that trait arousability is increased in people with schizophrenia, and that this may be related to stress responsiveness and symptom presentation.

The role of affect in the production of psychotic symptoms in war veterans is clear, and a majority of such cases meet criteria for major depressive disorder (David et al., 1999; Hamner et al., 1999).

Anxiety is also likely to be an important link. It is of interest that people with PTSD and those with schizophrenia both display abnormal startle responses (Howard \& Ford, 1992). Priebe et al. (1998) found that, in community patients with schizophrenia, PTSD was related to levels of neurotic symptoms. Crittendon \& Ainsworth (1989) demonstrated that children who have been abused or bullied are hypervigilant to hostile cues in their environment. This may lead such children to make hostile attributions about the intentions of others, and they may, not unreasonably, have more general negative beliefs about the behaviour of other people. Lysaker \& Salyers (2007) used cluster analysis to examine links between trauma history and symptoms in schizophrenia. They found that self-report of sexual trauma predicted high levels of anxiety, and severe anxiety was particularly associated with severe hallucinations.

However, the effect of a stressful early environment may equally be mediated through enduring cognitive predispositions, that is to say, a mechanism at the psychological level. Bak et al. (2005) examined the link between childhood trauma and incident psychosis. Trauma was associated with a greater degree of distress in response to symptoms and poorer coping responses (Bak et al., 2005). The authors conclude that the early experience of trauma may create lasting cognitive and affective vulnerabilities for the development of clinical symptoms. Gracie et al. (2007) found support for two separate routes 
linking trauma and the predisposition to psychosis. One involved mediation by negative beliefs about the self and others. However, there also appeared to be a second, direct, association between re-experiencing symptoms and hallucinations.

We now have a considerable amount of suggestive evidence about the nature of vulnerability to psychosis. The picture is complex, with interacting contributions at genetic, neurophysiological, behavioural, cognitive and emotional levels. The mechanisms of vulnerability may overlap extensively the mechanisms involved in the actual generation of psychotic symptoms, and vulnerability may sometimes be a repetitive rather than an enduring state. The idea of a repetitive state lends itself to a dynamic rather than a static interpretation, and is reflected in the idea of a continuum propensity to psychosis. While we have hints of how sexual abuse may be tied into the various mechanisms of vulnerability, this seems a topic ripe for research.

\section{Vulnerability and the continuum theory of psychosis}

Schizophrenia (and psychosis in general) is increasingly seen as the extreme end of abnormalities distributed continuously in the general population (Johns et al., 2004; Freeman et al., 2005; Wiles et al., 2006). Paranoid ideation of a mild degree and schizotypy are regarded as minor variants of the full form of the disorder. If so, sexual abuse might also be expected to be linked with subclinical symptoms. There is evidence that the determinants of the non-clinical disorders are similar to those of the full form (Johns et al., 2004). For example, Berenbaum et al. (2003) found that women with a history of trauma had elevated levels of schizotypal symptoms. The relationship seemed particularly strong for reported childhood neglect. In a large population sample, sub-psychotic delusional ideation was more frequent in people who had experienced trauma (Scott et al., 2007). A diagnosis of PTSD further increased the endorsement of delusional ideation. In adolescent populations childhood bullying and sexual trauma have been associated with sub-clinical quasi-psychotic experiences, and these might indicate risk of later conversion to frank psychotic disorder (Lataster et al., 2006; Schreier et al., 2009).

Thus, people can be conceived as moving along continuous distributions at different times, moving far enough on occasion to develop the full syndrome. This makes it appropriate to regard schizotypy itself as a vulnerability state, and therefore likely to yield insights into the causation of schizophrenia.
Marzillier \& Steel (2007) reported that people seeking help to deal with a traumatic event who scored high on schizotypy had more frequent trauma-related intrusions and worse symptoms of PTSD in general. Certain information processing styles associated with schizotypy may account for vulnerability to trauma-related intrusions (Marzillier \& Steel, 2007).

Steel et al. (2005) emphasise the possible role of contextual integration on the development of trauma-related intrusions in psychosis. Schizotypal personality traits are associated with the degree of contextual integration, and also with trauma-related intrusions. There seemed to be a dose-response relationship between the numbers of traumatic events and the likelihood of delusional experiences. Holmes \& Steel (2004) used a trauma video to elicit trauma intrusions in a normal sample. People who scored high on schizotypy reported more intrusive experiences as a result of this. The authors link this propensity with the influence of trauma on psychotic disorders.

\section{Trauma, meaning and psychotic symptoms}

Some authors have reported series of cases where the psychotic phenomena are obviously related in a meaningful way to the trauma. Thus, Ivezic et al. (1999) emphasize the strong symbolic relationship, the meaningful connection with the experience. Likewise, David et al. (1999) reported that in Vietnam veterans, the psychotic symptoms were related to aspects of combat and to guilt, averring that the relationship was 'non-bizarre'. However, the level of psychotic symptoms was not related to the severity of PTSD.

A meaningful connection between an external event or set of events and a psychiatric symptom might be said to exist if the characteristics of the event and the content of the symptom are thematically consistent. This can be conceived as the demand characteristics of the event. Early examples of attempt to establish meaningful links in this way include those between loss events and depression, and between danger events and anxiety (Brown \& Harris, 1978; Finlay-Jones \& Brown, 1981). In psychosis, links may exist between "intrusive" events and psychosis, particularly paranoid ideation (Harris, 1987; Raune et al., 2006; 2009). Such links can plausibly be made between the attributes of events and the context of delusions, whose very nature involves a consideration of the world. It is thus relatively easy to conceive that delusions may actually arise from a distorted process of appraisal. However, as we have seen, there is also work suggesting that there may be meaningful connections

Epidemiologia e Psichiatria Sociale, 18, 4, 2009 
between the nature of events and the content of hallucinations. Could this link also explain the fact of hallucination? In other words, could the thrust of the event distort the appraisal to the extent that the form of thinking becomes disturbed and externally projected? The current evidence on the effects of sexual abuse makes this idea less implausible.

\section{CONCLUSION}

There is now considerable evidence of an association between child sexual abuse and psychosis. This relationship is at least as strong as, and may be stronger than, that with other mental disorders. There may be a specific relationship with hallucinations. A history of severe trauma is common in people who develop psychosis, but the link between child sexual abuse and psychosis may be particularly strong, because of the age of the victim and the especially intrusive nature of the abuse. The mechanism of effect may overlap considerably with the triggering action of life events occurring in close proximity to the onset of psychosis. However, we also need an account of the maintenance of effect of child sexual abuse that can explain the establishment of a vulnerability that persists, sometimes for many years, before the actual onset of disorder. This may result from the impact of a series of intervening events and circumstances, and may be facilitated by processes like impaired coping responses, impaired access to appropriate social support, and revictimisation. Part of the mechanism of vulnerability seems likely to result from disturbances of affect and of cognitive schemas. Appreciation of the frequency and importance of child sexual abuse in individuals with psychosis could amplify their cognitive behavioural treatment.

\section{REFERENCES}

Adler, C.M., Elman I., Weisenfeld N., Kestler L., Pickar D. \& Breier A. (2000). Effects of acute metabolic stress on striatal dopamine release in healthy volunteers. Neuropsychopharmacology 22, 545-550.

Aguilar E.J., Haas G., Manzanera F.J., Hernández J., Gracia R., Rodado M.J. \& Keshavan M.S. (1997). Hopelessness and firstepisode psychosis: a longitudinal study. Acta Psychiatrica Scandinavica 96, 25-30.

Al Khani M.A.F., Bebbington P.E., Watson J.P. \& House F. (1986). Life events and schizophrenia: a Saudi Arabian study. British Journal of Psychiatry 148, 12-22.

Alloway R. \& Bebbington P.E. (1987). The buffer theory of social support: a review of the literature. Psychological Medicine 17, 91-108.

Arseneault L., Walsh E., Trzesniewski K., Newcombe R., Caspi A. \& Moffitt T.E. (2006). Bullying victimization uniquely contributes to adjustment problems in young children: a nationally representative cohort study. Pediatrics 118, 130-138.
Bak M., Krabbendam L., Janssen I., de Graaf R., Vollebergh W. \& van Os J. (2005). Early trauma may increase the risk for psychotic experiences by impacting on emotional response and perception of control. Acta Psychiatrica Scandinavica 112, 360-366.

Bebbington P.E., Wilkins S., Jones, P., Foerster A., Murray R., Toone B. \& Lewis S. (1993). Life events and psychosis: initial results from the Camberwell Collaborative Psychosis study. British Journal of Psychiatry 162, 72-79.

Bebbington P.E., Wilkins S., Sham P., Jones P., van Os J., Murray R., Toone B. \& Lewis S. (1996). Life events before psychotic episodes: do clinical and social variables affect the relationship? Social Psychiatry and Psychiatric Epidemiology 31, 122-128.

Bebbington P.E., Bhugra D., Brugha T., Farrell M., Lewis G., Meltzer H., Jenkins R., Lewis G. \& Meltzer H. (2004). Psychosis, victimisation and childhood disadvantage: evidence from the Second British National Survey of Psychiatric Epidemiology. British Journal of Psychiatry 185, 220-226.

Bebbington P.E., Cooper C., Minot S., Brugha T.S., Jenkins R., Meltzer H. \& Dennis M. (2009). Suicide attempts, gender and sexual abuse: Data from the British psychiatric morbidity survey 2000. American Journal of Psychiatry 166, 1135-1140.

Bentall R.P., Corcoran R., Howard R., Blackwood N. \& Kinderman P. (2001). Persecutory delusions: a review and theoretical integration. Clinical Psychological Review 21, 1143-1192.

Bentall R.P, Rowse G., Shryane N., Kinderman P., Howard R., Blackwood N., Moore R. \& Corcoran R. (2009). The cognitive and affective structure of paranoid delusions: a transdiagnostic investigation of patients with schizophrenic symptoms disclosure and depression. Archives of General Psychiatry 66, 236-247.

Berenbaum H., Valera E.M. \& Kerns J.G. (2003). Psychological trauma and schizotypal symptoms. Schizophrenia Bulletin 29, 143-152

Birchwood M. (2003). Pathways to emotional dysfunction in firstepisode psychosis. British Journal of Psychiatry 182, 373-375.

Birchwood M., McMillan F. \& Smith J. (1992). Early intervention. In Innovations in the Psychological Managment of Schizophrenia (ed. M. Birchwood and N. Tarrier), pp. 115-146. Wiley: Chichester.

Broome M.R., Woolley J.B., Tabraham P., Johns L.C., Bramon E., Murray G.K., Pariante C., McGuire P.K. \& Murray R.M. (2005). What causes the onset of psychosis? Schizophrenia Research 79, 23-34.

Brown G.W. \& Birley J.L.T. (1968). Crises and life changes and the onset of schizophrenia. Journal of Health and Social Behavior 9, 203-214.

Brown G.W. \& Harris T. (1978). Social Origins of Depression: A Study of Psychiatric Disorder in Women. Tavistock: London.

Brunner R., Parzer P., Schmitt R. \& Resch F. (2004). Dissociative symptoms in schizophrenia: a comparative analysis of patients with borderline personality disorder and healthy controls. Psychopathology 37, 281-284.

Butler R.W., Mueser K.T., Sprock J. \& Braff D.L. (1996). Positive symptoms of psychosis in post-traumatic stress disorder. Biological Psychiatry 39, 839-844.

Calhoun P.S., Stechuchak K.M., Strauss J., Bosworth H.B., Marx C.E. \& Butterfield M.I. (2007). Interpersonal trauma, war zone exposure, and posttraumatic stress disorder among veterans with schizophrenia. Schizophrenia Research 91, 210-216.

Castine M.R., Meador-Woodruff J.H. \& Dalack G.W. (1998). The role of life events in onset and recurrent episodes of schizophrenia and schizoaffective disorder. Journal of Psychiatric Research 32, 283-288.

Chung R.K., Langeluddecke P. \& Tennant C. (1986). Threatening life events in the onset of schizophrenia, schizophreniform psychosis and hypomania. British Journal of Psychiatry 148, 680-686.

Cooper C., Morgan C., Byrne M., Dazzan P., Morgan K., Hutchinson G., Doody G.A., Harrison G., Leff J., Jones P., Ismail K., Murray R., Bebbington P.E. \& Fearon P. (2008). Perceptions of social disadvantage, ethnicity and psychosis: results from the AESOP study. British Journal of Psychiatry 192, 185-190.

Cougnard A., Marcelis M., Myin-Germeys I., de Graaf R., Vollebergh W., Krabbendam L., Lieb R., Wittchen H.U., Henquet C., Spauwen J. \& van Os J. (2007). Does normal developmental expression of 
psychosis combine with environmental risk to cause persistence of psychosis? A psychosis proneness-persistence model. Psychological Medicine 37, 513-527.

Crittendon P.M. \& Ainsworth M.D.S. (1989). Child maltreatment \& attachment theory. In Childhood Maltreatment: Theory and Research on the Causes and Consequences of Child Abuse and Neglect (ed. D. Cicchetti and V. Carlson). Cambridge University Press: Cambridge.

David D., Kutcher G.S., Jackson E.I. \& Mellman T.A. (1999). Psychotic symptoms in combat-related post-traumatic stress disorder. Journal of Clinical Psychiatry 60, 29-32.

Day R., Neilsen J.A., Korten A., Ernberg G., Dube K.C., Gebhart J., Jablensky A., Leon C., Marsella A., Olatawura M. et al. (1987). Stressful life events preceding the acute onset of schizophrenia: a cross national study from the World Health Organization. Culture, Medicine and Psychiatry 11, 123-206.

Dinzeo T.J., Cohen A.S., Nienow T.M. \& Docherty N.M. (2004). Stress and arousability in schizophrenia. Schizophrenia Research 71, 127-135.

Doering S., Muller E., Kopcke W., Pietzcker A., Gaebel W., Linden M., Müller P., Müller-Spahn F., Tegeler J. \& Schüssler G. (1998). Predictors of relapse and rehospitalization in schizophrenia and schizoafective disorder. Schizophrenia Bulletin 24, 87-98.

Dohrenwend B.P., Levav I., Shrout P.E., Link B.G., Skodol A.E. \& Martin J.L. (1987). Life stress and psychopathology: progress with research begun with Barbara Snell Dohrenwend. American Journal of Community Psychology 15, 677-713.

Driessen M., Herrmann J., Stahl K., Zwaan M., Meier S., Hill A., Osterheider M. \&Petersen D. (2000). Magnetic resonance imaging volumes of the hippocampus and the amygdala in women with borderline personality disorder and early traumatization. Archives of General Psychiatry 57, 1115-1122.

Ellason J.E. \& Ross C.A. (1997). Childhood trauma and psychiatric symptoms. Psychological Reports 80, 447-450.

Finlay-Jones R. \& Brown G.W. (1981). Types of stressful life event and the onset of anxiety and depressive disorders. Psychological Medicine 11, 803-815.

Fowler D. (1999). The relationship between trauma and psychosis. Paper Presented at the Merseyside Psychotherapy Institute, Liverpool, May 1999.

Fowler D. (2000). Cognitive behavior therapy for psychosis: from understanding to treatment. Psychiatric Rehabilitation Skills 4, 199- 215.

Fowler D., Freeman D., Smith B., Kuipers E., Bebbington P., Bashforth H., Coker S., Gracie A., Dunn G. \& Garety P. (2006). The Brief Core Schema Scales (BCSS): Psychometric properties and associations with paranoia and grandiosity in non-clinical and psychosis samples. Psychological Medicine 36, 749-759.

Freeman D., Garety P.A., Bebbington P.E., Smith B., Rollinson R., Fowler D., Kuipers E., Ray K. \& Dunn G. (2005). Psychological investigation of the structure of paranoia in a non-clinical population. British Journal of Psychiatry 186, 427-435.

Friedman S., Smith L., Fogel D., Paradis C., Viswanathan R., Ackerman R. \& Trappler B. (2002). The incidence and influence of early traumatic life events in patients with panic disorder: a comparison with other psychiatric outpatients. Journal of Anxiety Disorders 16, 259-272.

Garety P., Kuipers E., Fowler D., Freeman D. \& Bebbington P. (2001). Theoretical paper: a cognitive model of the positive symptoms of psychosis. Psychological Medicine 31, 189-195.

Garety P.A., Freeman D., Jolley S., Dunn G., Bebbington P.E., Fowler D., Kuipers E. \& Dudley R. (2005). Reasoning, emotions and delusional conviction in psychosis. Journal of Abnormal Psychology 114, 373-384.

Garety P.A., Bebbington P., Fowler D., Freeman D. \& Kuipers E. (2007). Implications for neurobiological research of cognitive models of psychosis: a theoretical paper. Psychological Medicine 37, 1377-1391.

Gearon J.S., Kaltman S.I., Brown C. \& Bellack A.S. (2003). Traumatic life events and PTSD among women with substance use disorders and schizophrenia. Psychiatric Services 54, 523-528.
Glaslova K., Bob P., Jasova D., Bratkova N. \& Ptacek R. (2004). Traumatic stress and schizophrenia. Neurology Psychiatry and Brain Research 11, 205-208.

Goldman-Rakic P.S., Castner S.A., Svensson T.H., Siever L.J. \& Williams G.V. (2004). Targeting the dopamine D1 receptor in schizophrenia: insights for cognitive dysfunction. Psychopharmacology (Berl) 174, 3-16.

Goodman L.A., Thompson K.M., Weinfurt K., Corl S., Acker P., Mueser K.T. \& Rosenberg S.D. (1999). Reliability of reports of violent victimization and posttraumatic stress disorder among men and women with serious mental health. Journal of Trauma and Stress $12,587-599$.

Gracie A., Freeman D., Green S., Garety P.A., Kuipers E., Hardy A., Ray K., Dunn G., Bebbington P. \& Fowler D. (2007). The association between traumatic experience, paranoia and hallucinations: a test of the predictions of psychological models. Acta Psychiatrica Scandinavica 116, 280-289.

Gureje O. \& Adewumni A. (1988). Life events in schizophrenia in Nigerians: a controlled investigation. British Journal of Psychiatry 153, 367-375.

Hammersley P., Dias A., Todd G., Bowen-Jones K., Reilly B. \& Bentall R.P. (2003). Childhood trauma and hallucinations in bipolar affective disorder: preliminary investigation. British Journal of Psychiatry 182, 543-547.

Hamner M.B., Fruech B.C., Ulmer H.G. \& Arana G.W. (1999). Psychotic features and illness severity in combat veterans with chronic posttraumatic stress disorder. Biological Psychiatry 45, 846-852.

Hamner M.D., Frueh B.C., Ulmer H.G., Huber M.G., Twomey T.J., Tyson C. \& Arana G.W. (2000). Psychotic features in chronic posttraumatic stress disorder and schizophrenia: comparative severity. Journal of Nervous and Mental Disease 188, 217-221.

Hardy A., Fowler D., Freeman D., Smith B., Steel C., Evans J., Garety P., Kuipers E., Bebbington P. \& Dunn G. (2005). Trauma and hallucinatory experience in psychosis. Journal of Nervous and Mental Disease 193, 501-507.

Harris T. (1987). Recent developments in the study of life events in relation to psychiatric and physical disorders. In Psychiatric Epidemiology (ed. B. Cooper), pp. 81-103. Croom-Helm: London.

Heim C., Newport D.J., Miller A.H. \& Nemeroff C.B. (2000). Longterm neuroendocrine effects of childhood maltreatment. Journal of American Medical Association 284, 2321.

Hirsch S., Bowen J., Emami J., Cramer P., Jolley A., Haw C. \& Dickinson M. (1996). A one year prospective study of the effects of life events and medication in the etiology of schizophrenic relapse. British Journal of Psychiatry 168, 49-56.

Holmes E.A. \& Steel C. (2004). Schizotypy: a vulnerability factor for traumatic intrusions. Journal of Nervous and Mental Disease 192, 28-34.

Holowka D.W., King S., Saheb D., Pukall M. \& Brunet A. (2003). Childhood abuse and dissociative symptoms in adult schizophrenia. Schizophrenia Research 60, 87-90.

Horan W.P. \& Blanchard J.J. (2003). Emotional responses to psychosocial stress in schizophrenia: the role of individual differences in affective traits and coping. Schizophrenia Research 60, 271-283.

Horan W.P., Ventura J., Nuechterlein K.H., Subotnik K.L., Hwang S.S. \& Mintz J. (2005). Stressful life events in recent-onset schizophrenia: reduced frequencies and altered subjective appraisals. Schizophrenia Research 75, 363-374.

Horan W.P., Ventura J., Mintz J., Kopelowicz A., Wirshing D., Christian-Herman J., Foy D. \& Liberman R.P. (2007). Stress and coping responses to a natural disaster in people with schizophrenia. Psychiatry Research 151, 77-86.

Howard R. \& Ford R. (1992). From the jumping Frenchmen of Maine to post-traumatic stress disorder: the startle response in neuropsychiatry. Psychological Medicine 22, 695-707.

Hultman C.M., Wieselgren I.M. \& Ohman A. (1997). Relationships between social support, social coping and life events in the relapse of schizophrenic patients. Scandinavian Journal of Psychology 38, $3-13$.

Epidemiologia e Psichiatria Sociale, 18, 4, 2009 
Irwin H.J. (2001). The relationship between dissociative tendencies and schizotypy: an artifact of childhood trauma? Journal of Clinical Psychology 57, 331-342.

Ivezic S., Oruc L. \& Bell P. (1999). Psychotic symptoms in post-traumatic stress disorder. Military Medicine 164, 73-75.

Jacobs S. \& Myers J. (1976). Recent life events and acute schizophrenic psychosis: a controlled study. Journal of Nervous and Mental Disease 162, 75-87.

Janssen I., Krabbendam L., Bak M., Hanssen M., Vollebergh W., de Graaf R. \& van Os J. (2004). Childhood abuse as a risk factor for psychotic experiences. Acta Psychiatrica Scandinavica 109, 38-45.

Johns L.C., Cannon M., Singleton N., Murray R.M., Farrell M., Brugha T., Bebbington P., Jenkins R. \& Meltzer H. (2004). The prevalence and correlates of self-reported psychotic symptoms in the British population. British Journal of Psychiatry 185, 298-305.

Jones S.R. \& Fernyhough C. (2007). A new look at the neural diathesis-stress model of schizophrenia: the primacy of social-evaluative and uncontrollable situations. Schizophrenia Bulletin 33, 1171-1177.

Kapur S., Mizrahi R. \& Li M. (2005). From dopamine to salience to psychosis-linking biology, pharmacology and phenomenology of psychosis. Schizophrenia Research 79, 59-68.

Kilcommons A.M. \& Morrison A.P. (2005). Relationships between trauma and psychosis: an exploration of cognitive and dissociative factors. Acta Psychiatrica Scandinavica 112, 351-359.

Kinderman P. \& Cooke A. (2000). Recent Advances in Understanding Mental Illness and Psychotic Experiences. A report by the British Psychological Society Division of Clinical Psychology. British Psychological Society: Leicester.

Lappin J.M., Morgan K., Morgan C., Hutchison G., Chitnis X., Suckling J., Fearon P., McGuire P.K., Jones P.B., Leff J., Murray R.M. \& Dazzan P. (2006). Gray matter abnormalities associated with duration of untreated psychosis. Schizophrenia Research 83, 145-153.

Lataster T., van Os J., Drukker M., Henquet C., Feron F., Gunther N. \& Myin-Germeys I. (2006). Childhood victimisation and developmental expression of non-clinical delusional ideation and hallucinatory experiences: victimisation and non-clinical psychotic experiences. Social Psychiatry and Psychiatric Epidemiology 41, 423-428.

Lysaker P.H. \& Salyers M.P. (2007). Anxiety symptoms in schizophrenia spectrum disorders: associations with social function, positive and negative symptoms, hope and trauma history. Acta Psychiatrica Scandinavica 116, 290-298.

Lysaker P.H., Meyer P.S., Evans J.D., Clements C.A. \& Marks K.A. (2001). Childhood sexual trauma and psychosocial functioning in adults with schizophrenia. Psychiatric Services 52, 1485-1488.

MacDonald E.M., Pica S., McDonald S., Hayes R.L. \& Baglioni A.J. Jr (1998). Stress and coping in early psychosis: role of symptoms, selfefficacy, and social support in coping with stress. British Journal of Psychiatry 172, Suppl. 33, 122-127.

Malla A.K., Cortese L., Shaw T.S. \& Ginsberg B. (1990). Life events and relapse in schizophrenia: a one year prospective study. Social Psychiatry and Psychiatric Epidemiology 25, 221-224.

Malzacher M., Merz J. \& Ebnother D. (1981). Einschneidende Lebensereignisse im Vorfeld akuter schizophrener Episoden: Erstmals erkrankte Patienten im Vergleich mit einer Normalstichprobe. Archiv Fur Psychiatrie und Nervenkrankheiten 230, 227-242.

Marzillier S.L. \& Steel C. (2007). Positive schizotypy and trauma-related intrusions. Journal of Nervous and Mental Disease 195, 60-64.

May-Chahal C. \& Cawson P. (2005). Measuring child maltreatment in the United Kingdom: a study of the prevalence of child abuse and neglect. Child Abuse \&Neglect 29, 969-984.

Mazure C.M., Quinlan D.M. \& Bowers M.B., Jr. (1997). Recent life stressors and biological markers in newly admitted psychotic patients. Biological Psychiatry 41, 865-870.

Morgan C. \& Fearon P. (2007). Social experience and psychosis: insights from studies of migrant and ethnic minority groups. Epidemiologia e Psichiatria Sociale 16, 118-123.
Morgan C. \& Fisher H. (2007). Environment and schizophrenia: environmental factors in schizophrenia: childhood trauma: a critical review. Schizophrenia Bulletin 33, 3-10.

Morrison A.P. (2001). The interpretation of intrusions in psychosis: an integrative cognitive approach to hallucinations and delusions. Behavioural \& Cognitive Psychotherapy 29, 257-276.

Mueser K.T., Goodman L.B., Trumbetta S.L., Rosenberg S.D., Osher C., Vidaver R., Auciello P. \& Foy D.W. (1998). Trauma and posttraumatic stress disorder in severe mental illness. Journal of Consulting and Clinical Psychology 66, 493-499.

Mueser K.T., Rosenberg S.D., Goodman L.A. \& Trumbetta S.L. (2002). Trauma, PTSD, and the course of severe mental illness: an interactive model. Schizophrenia Research 53, 123-143.

Myin-Germeys I. \& van Os J. (2007). Stress-reactivity in psychosis: evidence for an affective pathway to psychosis. Clinical Psychology Review 27, 409-424.

Myin-Germeys I., Krabbendam L., Delespaul P. \& van Os J. (2003). Can cognitive deficits explain differential sensitivity to life events in psychosis? Social Psychiatry and Psychiatric Epidemiology 38, 262-268.

Myin-Germeys I., Delespaul P. \& van Os J. (2005). Behavioural sensitization to daily life stress in psychosis. Psychological Medicine 35, 733-741.

Neria Y., Bromet E.J., Sievers S., Lavelle J. \& Fochtmann L.J. (2002). Trauma exposure and posttraumatic stress disorder in psychosis: findings from a first-admission cohort. Journal of Consulting and Clinical Psychology 70, 246-251.

Pallanti S., Quercioli L. \& Pazzagli A. (1997). Relapse in young paranoid schizophrenic patients: a prospective study of stressful life events. American Journal of Psychiatry 154, 792-298.

Pariante C.M., Dazzan P., Danese A., Morgan K.D., Brudaglio F., Morgan C., Fearon P., Orr K., Hutchinson G., Pantelis C., Velakoulis D., Jones P.B., Leff J. \& Murray R.M. (2005). Increased pituitary volume in antipsychotic-free and antipsychotic-treated patients of the AESOP first-onset psychosis study. Neuropsychopharmacology 30, 1923-1931.

Penn D.L., Mueser K.T., Tarrier N., Gloege A., Cather C., Serrano D. \& Otto M.W. (2004). Supportive therapy for schizophrenia: possible mechanisms and implications for adjunctive psychosocial treatments. Schizophrenia Bulletin 30, 101-112.

Priebe S., Broker M. \& Gunkel S. (1998). Involuntary admission and post-traumatic stress disorder symptoms in schizophrenia patients. Comprehensive Psychiatry 39, 220-224.

Pruessner J.C., Champagne F., Meaney M.J. \& Dagher A. (2004). Dopamine release in response to a psychological stress in humans and its relationship to early life maternal care: a positron emission tomography study using [11C]raclopride. Journal of Neuroscience $24,2825-2831$.

Ramana R. \& Bebbington P. (1995). Social influences on bipolar affective disorders. Social Psychiatry and Psychiatric Epidemiology 30, 152-160.

Raune D., Bebbington P., Dunn G.D. \& Kuipers E. (2006). Event attributes and the content of psychotic experiences in first episode psychosis. Psychological Medicine 188, 221-230.

Raune D., Bebbington P.E. \& Kuipers E.A. (2009). Stressful and intrusive life events preceding first episode psychosis. Epidemiologia e Psichiatria Sociale 18, 221-228.

Read J., Perry B. D., Moskowitz A. \& Connolly J. (2001). The contribution of early traumatic events to schizophrenia in some patients: a traumagenic neurodevelopmental model. Psychiatry 64, 319-345.

Read J., Agar K., Argyle N. \& Aderhold V. (2003). Sexual and physical abuse during childhood and adulthood as predictors of hallucinations, delusions and thought disorder. Psychology and Psychotherapy-Theory Research and Practice 76, 1-22.

Read J., van Os J., Morrison A.P. \& Ross C.A. (2005). Childhood trauma, psychosis and schizophrenia: a literature review with theoretical and clinical implications. Acta Psychiatrica Scandinavica 112, 330-350.

Resnick S.G., Bond G.R. \& Mueser K.T. (2003). Trauma and posttraumatic stress disorder in people with schizophrenia. Journal of Abnormal Psychology 112, 415-423.

Epidemiologia e Psichiatria Sociale, 18, 4, 2009 
Ryan M.C., Sharifi N., Condren R.; \& Thakore J.H. (2004). Evidence of basal pituitary-adrenal overactivity in first episode, drug naive patients with schizophrenia. Psychoneuroendocrinology 29, 10651070.

Scheller-Gilkey G., Moynes K., Cooper I., Kant C. \& Miller A.H. (2004). Early life stress and PTSD symptoms in patients with comorbid schizophrenia and substance abuse. Schizophrenia Research 69, 167-174.

Schreier A., Wolke D., Thomas K., Horwood J., Hollis C., Gunnell. D., Lewis G., Thompson A., Zammit S., Duffy L., Salvi. G. \& Harrison G. (2009). Prospective study of peer victimization in childhood and psychotic symptoms in a nonclinical population at age 12 years. Archives of General Psychiatry 66, 527-536.

Scott J., Chant D., Andrews G., Martin G. \& McGrath J. (2007). Association between trauma exposure and delusional experiences in a large community-based sample. British Journal of Psychiatry 190, 339-343.

Seedat S., Stein M.B., Oosthuizen P.P., Emsley R.A. \& Stein D.J. (2003). Linking posttraumatic stress disorder and psychosis: a look at epidemiology, phenomenology, and treatment. Journal of Nervous and Mental Disease 191, 675-681.

Shenton M.E., Dickey C.C., Frumin M. \& McCarley R.W. (2001). A review of MRI findings in schizophrenia. Schizophrenia Research $49,1-52$.

Shevlin M., Dorahy M. \& Adamson G. (2007). Childhood traumas and hallucinations: an analysis of the National Comorbidity Survey. Journal of Psychiatric Research 41, 222-228.

Smith B., Fowler D.G., Freeman D., Bebbington P., Bashforth H., Garety P., Dunn G. \& Kuipers E. (2006). Emotion and psychosis: Links between depression, self-esteem, negative schematic beliefs and delusions and hallucinations. Schizophrenia Research 86, 181-188.
Spauwen J., Krabbendam L., Lieb R., Wittchen H.U. \& van Os J. (2006). Impact of psychological trauma on the development of psychotic symptoms: relationship with psychosis proneness. British Journal of Psychiatry 188, 527-533

Steel C., Fowler D. \& Holmes E.A. (2005). Trauma-related intrusions and psychosis: An information processing account. Behavioural and Cognitive Psychotherapy 33, 139-152.

Tosato S. \& Lasalvia A. (2009). The contribution of epidemiology to defining the most appropriate approach to genetic research on schizophrenia. Epidemiologia e Psichiatria Sociale 18, 81-90.

Tienari P., Wynne L.C., Moring J., Lahti I., Naarala M., Sorri A., Wahlberg K.E., Saarento O., Seitamaa M., Kaleva M. et al. (1994). The Finnish adoptive family study of schizophrenia: implications for family research. British Journal of Psychiatry, Suppl. 23, 20-26.

Ucok A. \& Bikmaz S. (2007). The effects of childhood trauma in patients with first-episode schizophrenia. Acta Psychiatrica Scandinavica $116,371-377$

Ventura J., Nuechterlein K.H., Lukoff D. \& Hardisty J.P. (1989). A prospective study of stressful life events and schizophrenic relapse. Journal of Abnormal Psychology 98, 407-404.

Ventura J., Nuechterlein K.H., Subotnik K.L., Hardesty J.P. \& Mintz J. (2000). Live events can trigger depressive exacerbation in the early course of schizophrenia. Journal of Abnormal Psychology 109, 139144.

Yung A.R. \& McGorry P.D. (1996). The initial prodrome in psychosis: descriptive and qualitative aspects. Australian and New Zealand Journal of Psychiatry 30, 587-599.

Wiles N.J., Zammit S., Bebbington P., Singleton N., Meltzer H. \& Lewis G. (2006). Self-reported psychotic symptoms in the general population. British Journal of Psychiatry 188, 519-526. 